\title{
Numerical Simulation for Mechanical Behavior of U10Mo Monolithic Miniplates for Research and Test Reactors
}

\author{
IMECE 2011
}

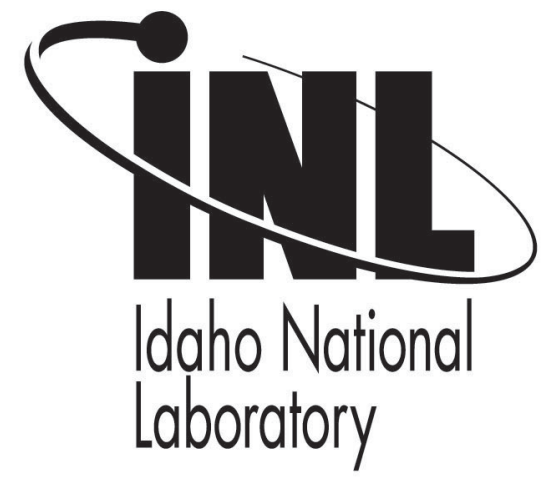

This is a preprint of a paper intended for publication in a journal or proceedings. Since changes may be made before publication, this preprint should not be cited or reproduced without permission of the author. This document was prepared as an account of work sponsored by an agency of the United States Government. Neither the United States Government nor any agency thereof, or any of their employees, makes any warranty, expressed or implied, or assumes any legal liability or responsibility for any third party's use, or the results of such use, of any information, apparatus, product or process disclosed in this report, or represents that its use by such third party would not infringe privately owned rights. The views expressed in this paper are not necessarily those of the United States Government or the sponsoring agency. 


\section{NUMERICAL SIMULATION FOR MECHANICAL BEHAVIOR OF U10MO MONOLITHIC MINIPLATES FOR RESEARCH AND TEST REACTORS}

\author{
Hakan Ozaltun \& Herman Shen \\ Department of Mechanical Engineering \\ Ohio State University, 201 W. 19th Avenue \\ Columbus/OH - 43210, USA
}

\author{
Pavel Medvedev \\ Material and Fuel Complex \\ Idaho National Laboratory, P.O. Box 1625 \\ Idaho Falls/ID - 83415, USA
}

\begin{abstract}
This article presents assessment of the mechanical behavior of U-10wt\% Mo (U10Mo) alloy based monolithic fuel plates subject to irradiation. Monolithic, plate-type fuel is a new fuel form being developed for research and test reactors to achieve higher uranium densities within the reactor core to allow the use of low-enriched uranium fuel in high-performance reactors. Identification of the stress/strain characteristics is important for understanding the in-reactor performance of these plate-type fuels. For this work, three distinct cases were considered: (1) fabrication induced residual stresses (2) thermal cycling of fabricated plates; and finally (3) transient mechanical behavior under actual operating conditions. Because the temperatures approach the melting temperature of the cladding during the fabrication and thermal cycling, high temperature material properties were incorporated to improve the accuracy. Once residual stress fields due to fabrication process were identified, solution was used as initial state for the subsequent simulations. For thermal cycling simulation, elasto-plastic material model with thermal creep was constructed and residual stresses caused by the fabrication process were included. For in-service simulation, coupled fluid-thermal-structural interaction was considered. First, temperature field on the plates was calculated and this field was used to compute the thermal stresses. For time dependent mechanical behavior, thermal creep of cladding, volumetric swelling and fission induced creep of the fuel foil were considered. The analysis showed that the stresses evolve very rapidly in the reactor. While swelling of the foil increases the stress of the foil, irradiation induced creep causes stress relaxation.
\end{abstract}

Keywords: Hot Isostatic Pressing, Blister Annealing, Thermal Creep, Irradiation Enhanced Creep, Swelling

Corresponding author. Tel: +1.614.2922280 | Fax: +1.614.2928290

E-mail address: shen.1@osu.edu (Prof. Herman Shen)

\section{INTRODUCTION}

Initiated in the late 1970's, the primary objective of the Reduced Enrichment for Research and Test Reactors (RERTR) program $^{1}$ is to develop technology to minimize the use of Highly Enriched Uranium (HEU) in civilian applications. The GTRI fuel development program aims to develop fuel types that would substitute highly enriched uranium with proliferation resistant, low enriched uranium $\left(<20 \%{ }^{235} \mathrm{U}\right)$ for research reactors [1]. Lower uranium enrichment requires higher fuel density in order to maintain reactor performance. Many research reactors can be satisfactorily operated with silicon based $\left(\mathrm{U}_{3} \mathrm{Si}_{2}-\mathrm{Al}\right)$ dispersion fuels with a fuel meat uranium density of $4.8 \mathrm{~g}-\mathrm{U} / \mathrm{cm}^{3}$. However, several high performance reactors require uranium densities of $\geq 8 \mathrm{~g}-\mathrm{U} / \mathrm{cm}^{3}$. These reactors require the use of high-density fuel alloys, either as dispersion fuels at high volume loading, or in monolithic form. Among several proposed alloys, U-Mo alloys are considered to be the most promising candidate for fuels of higher densities. Molybdenum extends the stability of the cubic gamma phase. This is desirable because this phase is known to be stable under typical irradiation conditions. U-Mo has a low neutron caption cross-section, good irradiation behavior, and acceptable swelling response [2-4].

Monolithic fuel plates comprised of U-Mo alloy based foils encapsulated in aluminum alloy cladding are proposed for conversion of some high performance research reactors to low enriched uranium fuel reactors. Three different fabrication techniques have been considered and evaluated at INL for the fabrication: Hot Isostatic Pressing (HIP), Friction Stir Welding (FSW), and Transient Liquid Phase Bonding (TLPB). Of these three techniques, the HIP technique has been selected for use because of its ability to consistently produce a strong, uniform

\footnotetext{
${ }^{1}$ Now known as (GTRI) Global Threat Reduction Initiative
} 
bond. As a result, this study focuses on monolithic plates fabricated via the HIP technique.

The typical process for fabricating monolithic fuel plates by HIP involves several steps. First, uranium and molybdenum feedstock is melted in an inert atmosphere and cast into thin coupons. The coupons are hot rolled at $\sim 650{ }^{\circ} \mathrm{C}$ and finished using cold rolling to achieve a final foil thickness of $0.250 \mathrm{~mm}$ (thickness varies depending on the reactor application). The foils are then annealed at $650-675{ }^{\circ} \mathrm{C}$ for $30-120$ minutes to eliminate residual stresses. The foil is placed between two layers of aluminum cladding material. For the RERTR fuel plates, Al6061-T0 is used as cladding. The three layers are subjected to a HIP procedure conducted at a temperature of 560 ${ }^{\circ} \mathrm{C}$ and a pressure of $104 \mathrm{MPa}$ for 90 minutes before being cooled to room temperature at a rate of $4.8{ }^{\circ} \mathrm{C} / \mathrm{min}$ with diminishing pressure as described in [5-7]. The final dimensions of the plate modeled in this paper are shown in Figure 1.
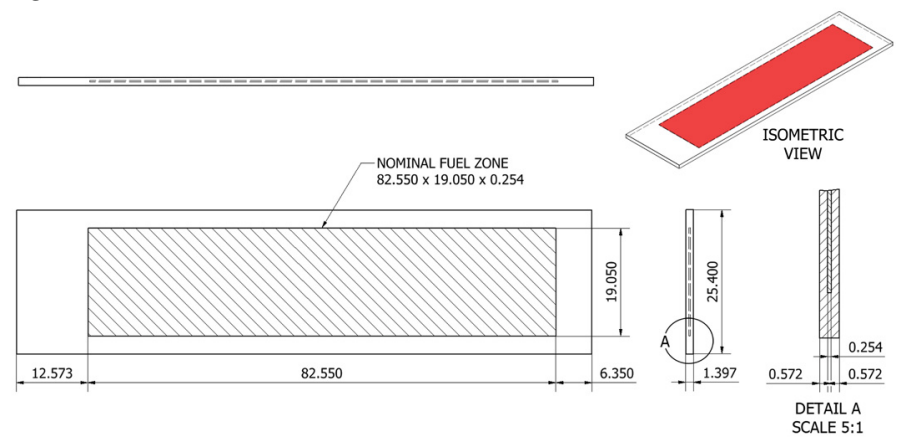

Figure 1 Dimensions [mm] of a mini-plate

To ensure the bonding quality, the miniplates are checked by UT (Ultrasonic Transmission) Scanning technique for the regions with poor bonding after the fabrication. Once mini plates are fabricated as described, total 32 mini plates are then assembled into 4 capsules made of Al6061-T6. The capsules are positioned vertically in a basket and are cooled by direct contact with primary coolant. Flow velocities over the plates are $11 \mathrm{~m} / \mathrm{sec}$ for outer channel and $14 \mathrm{~m} / \mathrm{sec}$ inner channel. Approximate pressure of the primary coolant is $2.56 \mathrm{MPa}$. A schematic of plate assembly is shown in Figure 2.

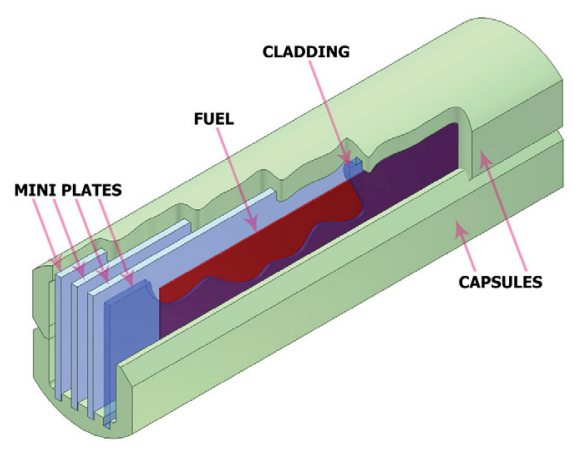

Figure 2 A plate assembly
Due to the vertical positioning in the reactor, fission densities on the plates are not uniform. One side of the plates (close to the reactor core) is exposed to higher fission densities. This profile (Fission density with respect to width of the plate) is shown in Figure 3a. Actual volumetric heat release rate during the experiments (98 days of irradiation) is shown in figure $3 \mathrm{~b}$. Because there is a power increase at day 51, simulations presented in this article consider the plates at both low power and high power. For this, plates were simulated at low power $\left(16500 \mathrm{~W} / \mathrm{cm}^{3}\right)$ for first 51 days. From day 51 to day 98 , volumetric heat release rate was increased to $19300 \mathrm{~W} / \mathrm{cm}^{3}$ to consider the plates at high power.

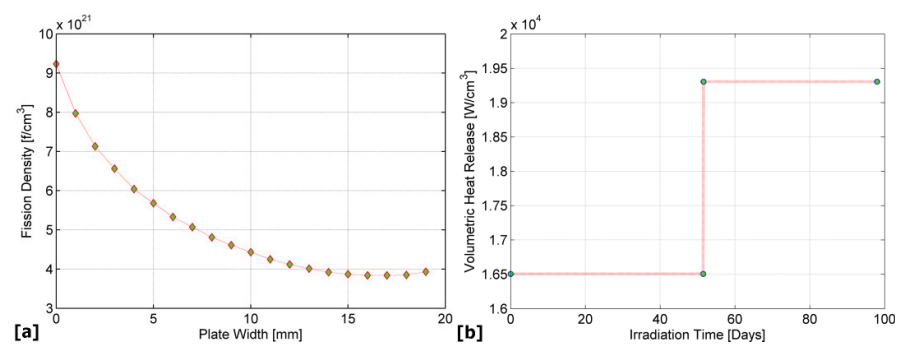

Figure 3 (a) Power profile (b) Volumetric heat generation

To ensure the safety, irradiated plates are exposed to several quality checks. Among many, thermal cycling so called "Blister Annealing" is a practice for the plate-type fuel elements which sets a safety margin. During the test, a specific threshold temperature, the temperature at where the specimen would produce blisters, is sought. To determine this temperature, specimens are exposed to several steps. For this, plates are heated in a furnace and visually examined for indication of any blisters. If there is none, then, plates are returned back to the furnace at higher temperatures. Same procedure is repeated until the plate produce blisters. This temperature is accepted as Blister or threshold temperature. For blister annealing of an irradiated plate, if it is blistered, these pores would be filled and swell with fission products and the specimen is assumed to be at breakaway point. Therefore, Blister temperature is treated as an evaluation mechanism for the failure prediction. This thermal cycling practice might be applied to both irradiated and unirradiated plates depending on the purpose of the experiment. This article considers the thermal cycling of the unirradiated plates, due to the lack of material property data. It is expected that the pre-blister stress pattern in irradiated foils would be different. However, similar principles presented in this article can be applied for the Blister simulation of irradiated plates, when the material data of irradiated fuel becomes available.

\section{MODELLING}

\subsection{MATHEMATICAL PRELIMINARIES}

Material properties were assumed to be isotropic. However, temperature dependency was considered. The modulus, Poisson's ratio and shear modulus were defined as; 


$$
\begin{aligned}
& E_{x}=E_{y}=E_{z}=E(T) \\
& v_{x y}=v_{y x}=v_{x z}=v_{z x}=v_{y z}=v_{z y}=v(T) \\
& G_{x y}=G_{x z}=G_{y z}=\frac{E(T)}{2 \cdot[1+v(T)]}
\end{aligned}
$$

The linearized form of the strain tensor can be expressed as,

$\varepsilon_{i j}^{\text {total }}=\frac{1}{2}\left(\frac{\partial u_{i}}{\partial u_{j}}+\frac{\partial u_{j}}{\partial u_{i}}\right)$

where, $\varepsilon_{i j}$ and $u_{i j}$ are strain tensor and displacements respectively. At each point in the plate, the total-strain component $\varepsilon^{\text {total }}$ can be expressed as the sum of the corresponding components of the elastic, plastic, thermal, creep (thermal creep and irradiation creep), swelling and initial strains as follows,

$\varepsilon_{i j}^{t o t a l}=\varepsilon_{i j}^{e l}+\varepsilon_{i j}^{p l}+\varepsilon_{i j}^{t h}+\varepsilon_{i j}^{c r}+\varepsilon_{i j}^{s w}+\varepsilon_{i j}^{i n}$

The stress/strain relation of the plate can be expressed as,

$\sigma_{i j}=D_{i j k l} \times \varepsilon_{k l}^{e l}+\sigma_{i j}^{i n}$

where $D_{i j k l}$ is $6 x 6$ temperature dependent elasticity matrix, $\mathcal{\varepsilon}_{k l}^{e l}$ elastic strain tensor, and $\sigma_{i j}^{i n}$ is the initial stress (i.e. residual stress). Substituting elastic strains from (5) into the relation in (6) yields,

$\sigma_{i j}=D_{i j k l} \times\left(\varepsilon_{k l}^{\text {total }}-\varepsilon_{k l}^{p l}-\varepsilon_{k l}^{t h}-\varepsilon_{k l}^{c r}-\varepsilon_{k l}^{s w}-\varepsilon_{k l}^{i n}\right)+\sigma_{i j}^{i n}$

The yield is defined according to Von-Mises criteria as follows,

$F_{d}\left(\sigma_{i j}, \bar{\varepsilon}\right)=\frac{1}{2} \sigma_{i j}^{\prime} \sigma_{i j}^{\prime}-\frac{1}{3} \sigma_{s}^{2}(\bar{\varepsilon})$

$\sigma_{e q}=\sqrt{\frac{3}{2} \sigma_{i j}^{\prime} \sigma_{i j}^{\prime}} \geq \sigma_{s}$

where $\sigma_{i j}^{\prime}$ is the deviatoric part of Kirchhoff stress, $\bar{\varepsilon}$ represents the equivalent plastic strain, $\sigma_{e q}$ is the equivalent stress and $\sigma_{s}$ is the yield stress of the material.

The thermal strain tensor $\varepsilon_{k l}^{t h}$ is expressed by,

$\varepsilon_{i j}^{t h}=\alpha_{i j}(T) \times \Delta T$ where $\alpha$ is the tensor governs the coefficient of thermal expansion, and $\Delta T$ is the change in temperature.

\section{Volumetric Swelling Strain}

Incremental swelling strain is defined as

$\Delta \varepsilon^{s w}=\frac{1}{3} \Delta \bar{\varepsilon}^{s w} \Re$

$\dot{\mathcal{E}}_{A}^{s w}=\dot{\mathcal{E}}_{11}^{s w}+\dot{\mathcal{E}}_{22}^{s w}+\dot{\mathcal{E}}_{33}^{s w}=\frac{1}{3}\left(r_{11}+r_{22}+r_{33}\right) \dot{\mathcal{E}}_{\text {total }}^{s w}$

$\mathfrak{R}$ is a matrix with the anisotropic swelling ratios in the diagonal. Volumetric swelling strain rate is $\dot{\varepsilon}_{\text {total }}^{s w}$ and $r_{11}, r_{22}$ and $r_{33}$ are the directions of the components of the swelling strain rate. For miniplates, swelling was assumed to be isotropic and therefore $\mathfrak{R}=\mathbf{I}$.

Volumetric swelling is the sum of the swellings due to solid and gaseous products. It is defined in [8] as follows;

$\left(\frac{\Delta V}{V_{0}}\right)_{\text {total }}=\left(\frac{\Delta V}{V_{0}}\right)_{g}+\left(\frac{\Delta V}{V_{0}}\right)_{s}$

Solid fission swelling [8] was defined according to;

$\left(\frac{\Delta V}{V_{0}}\right)_{s}=3.5 \times 10^{-21} \cdot f_{d}$

Similarly, gas bubble swelling [8] was formulated as;

$\left(\frac{\Delta V}{V_{0}}\right)_{g}=0.5 \times 10^{-21} \cdot f_{d} \quad$ if $\quad f_{d}<3 \times 10^{21} \mathrm{f} / \mathrm{cm}^{3}$

$\left(\frac{\Delta V}{V_{0}}\right)_{g}=5.4+2.2 \times 10^{-21} \cdot\left(f_{d}-3 \times 10^{21}\right)+0.51 \times 10^{-42} \times\left(f_{d}-3 \times 10^{21}\right)^{2}$

\section{Thermal Creep Strain}

The thermal creep strain tensor, $\mathcal{E}^{c r}$ was expressed using a power law relationship as follows,

$\dot{\overline{\mathcal{E}}}^{c r}=A \tilde{\sigma}^{n} t^{m}$

where $\dot{\bar{\varepsilon}}^{c r}$ is the uniaxial equivalent creep strain rate; $\tilde{\sigma}$ is the equivalent deviatoric stress; $t$ is the total time, and $A, n, m$ are material parameters. The values of the material parameters were obtained by a mathematical fitting to the material data 
presented in Appendix A. The creep model assumes that some inelastic deformation would occur whenever the stress in the material is nonzero.

\section{Fission Induced Creep Strain}

Irradiation-induced creep of fuel material is based on an empirical model which relates the creep rate to the fast neutron flux $\Phi$ [neutron $/ \mathrm{m}^{2}$.s] and amplitude of the equivalent stress $\sigma$ [MPa]. This specific relation is in power form as follows,

$\left(\frac{d \varepsilon}{d t}\right)_{i r}^{c r}=K \cdot \sigma^{n} \cdot \Phi^{p}$

The parameter $K\left(\mathrm{~m}^{2} /\right.$ neutron.Pa), exponents $n$ and $p$ are determined from the results of the relaxation experiments. Proposed fission enhanced creep formulation [9] represents the irradiation creep strain in terms of the fission density rate;

$\left(\frac{d \varepsilon}{d t}\right)_{i r}^{c r}=A \sigma \dot{F}$

Where $\sigma$ is equivalent stress [MPa]; $A$ is a material parameter $\left(A=2.5 \times 10^{-25}\left[\mathrm{~cm}^{3} /\right.\right.$ fission.MPa $)$ and $\dot{F}$ is the average fission density rate $\left[\right.$ fission $\left./\left(\mathrm{cm}^{3} \cdot \mathrm{sec}\right)\right]$ in the plate [9].

\section{Thermal Transport}

The governing equation for pure conductive heat transfer is expressed as;

$\rho C_{p} \frac{\partial T}{\partial t}+\nabla \cdot(-k \nabla T)=Q-\rho C_{p} \mathrm{u} \cdot \nabla T$

Where $\rho$ is the density, $C_{p}$ is the specific heat capacity at constant pressure, $T$ is absolute temperature, $k$ is the thermal conductivity, $u$ is the velocity vector, $Q$ is the heat sources other than viscous heating. For solid, $u$ (velocity vector) is set to be zero and therefore, governing equation for pure conductive heat transfer in fuel foil and cladding is,

$\rho C_{p} \frac{\partial T}{\partial t}+\nabla \cdot(-k \nabla T)=Q$

Heat transfer coefficient between the bulk of the fluid and the cladding surface was computed via Dittus-Boelter correlation;

$h=\frac{k_{w}}{D_{H}} N u$

Where $k_{w}$ thermal conductivity of the coolant, $D_{H}$ is hydraulic diameter and $\mathrm{Nu}$ is Nusselt number expressed as;
$N u=0.023 \cdot R e^{0.8} \cdot \operatorname{Pr}^{n}$

Where $R e$ is Reynolds number, $P r$ is Prandtl number and finally $n=0.4$ (heating of the coolant).

\section{Fluid Flow}

Generalized version of the Navier-Stokes equations was solved over the domain to allow for variable viscosity. Starting with the momentum balance in terms of stresses, the generalized equations in terms of transport properties and velocity gradients can be expressed in momentum transport equation defined as follows;

$\rho \frac{\partial u}{\partial t}-\nabla \cdot\left[\eta\left(\nabla u+(\nabla u)^{T}\right)\right]+\rho(u \cdot \nabla) u+\nabla p=F$

Equation of continuity for incompressible fluids is;

$$
\nabla \cdot u=0
$$

Where $\eta$ is the dynamic viscosity, $\rho$ is the density, $u$ is the velocity field, $P$ is the pressure and $F$ is volume force field. Temperature dependent data for viscosity and density was used to allow the thermal effects.

\subsection{FINITE ELEMENT MODEL}

There are a number of published works investigating thermal stresses in multi-layered structures [10-13]. The mechanical behavior of the proposed monolithic fuel plates has not been modeled. A general-purpose commercial finite element solver, ABAQUS, and computational clusters at the Ohio Super Computing Center (OSC) were utilized for this work. Due to symmetry, only one-half of the plate (cut through the XY midplane) was modeled as shown in Figure 4.

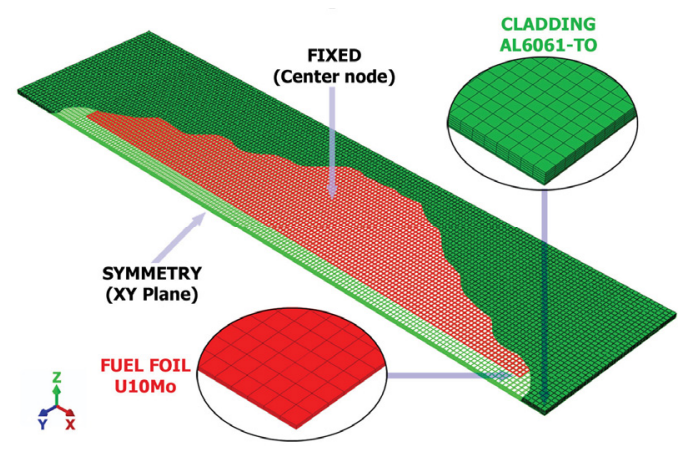

Figure 4 Half symmetric finite element model

The C3D8RT element in ABAQUS, an 8-node thermally coupled brick, tri-linear displacement and temperature with reduced integration and hourglass control, was used. The fuel was represented by using 13500 hexahedral elements and 
18724 nodes in 3 layers, while the cladding contained 44100 hexahedral elements and 53826 nodes in 8 layers (totaling 57600 elements with 72550 nodes). Nodal points at the foil/cladding interface were connected with a tie constraint. On the mid-plane, a symmetry condition was assigned to corresponding nodes. The node at the volumetric center was fixed to prevent rigid body motion. U-10Mo material properties were assigned to the fuel foil region and Al6061-T0 material properties [14-23] were assigned to the cladding region. Elastothermo-perfectly-plastic material constitution was chosen for both cladding and fuel materials to incorporate plasticity. Material yield was defined according to Von-Mises criteria. Because fuel foils are fabricated separately and subjected to an annealing treatment, the foil is modeled as initially stress free.

3 distinct simulations were considered. HIP simulation to identify the residual stress fields on the plates, Irradiation Simulation for identification of the transient behavior and finally Blister simulation to characterize the mechanical behavior of the plates due to the thermal annealing.

HIP simulation considers cooling stage of the fabrication process. During the cooling process, the temperature of the plate is reduced from exact bonding temperature $\left(560{ }^{\circ} \mathrm{C}\right)$ to room temperature $\left(21{ }^{\circ} \mathrm{C}\right)$ with $4.8{ }^{\circ} \mathrm{C} / \mathrm{min}$ cooling rate. Resulting residual stress field was used as initial condition for Irradiation and Thermal Annealing simulations.

Thermal Annealing presented in this article considers 3 distinct stages. Heating (from $21{ }^{\circ} \mathrm{C}$ to $500{ }^{\circ} \mathrm{C}$ with $4.8{ }^{\circ} \mathrm{C} / \mathrm{min}$ heating rate), holding $\left(60\right.$ minutes at $500{ }^{\circ} \mathrm{C}$ ) and cooling (from $500{ }^{\circ} \mathrm{C}$ to $21{ }^{\circ} \mathrm{C}$ with $4.8{ }^{\circ} \mathrm{C} / \mathrm{min}$ cooling rate) including residual stress field caused by the fabrication process.

Irradiation Simulation considers the plates for 98 days in reactor. The power profile with respect to plate width (shown in Figure 3a) and volumetric heat generation rate with respect to time (shown in Figure 3b) were implemented in to finite element formulation via parametric expressions and they were assigned to the fuel region. Irradiation induced creep (for U10Mo), swelling strain rate (for U10Mo), heat generation and its swelling update (for U10Mo), thermal creep (for Al6061TO) formulations were implemented in to the finite element model. Results were stored for every 24 hours of irradiation.

To incorporate the non-linear volumetric swelling rate, a user defined subroutine was developed. This relation was implemented to the fuel region via user defined FORTRAN subroutine CREEP. As initial state, residual stress field (from HIP simulation) was assigned to the corresponding nodes via predefined field. Top side of the plate (interface of the cladding and coolant) coolant film condition was assigned. Heat transfer coefficient was computed via Dittus-Boelter formulation, commonly used and relatively simple correlation. From thin sides of the plates, heat transfer was assumed to be small to reduce the computational time.

\section{RESULTS AND DISCUSSIONS}

\subsection{HIP SIMULATION and RESIDUAL STRESSES}

To capture the irradiation behavior more accurately, fabrication induced residual stresses were computed via HIP simulation. HIP simulation considers a thermal-structural interaction to compute the thermal stresses on the plates. Residual stresses due to the fabrication served as an initial condition for all proceeding simulations. To determine the stress-strain characteristics during this process, the plates were simulated from $560{ }^{\circ} \mathrm{C}$ to $21{ }^{\circ} \mathrm{C}$ with the cooling rate of $4.8{ }^{\circ} \mathrm{C} / \mathrm{min}$. Results were stored for every 5 minutes interval.

Figure 5 presents the calculated displacements and equivalent stresses during the entire cooling process. Figure 5a implies that the fuel exhibits $1.13 \mathrm{~mm}$ total displacement while the cladding displaces approximately $1.50 \mathrm{~mm}$. Displacements for both fuel foil and cladding materials follow more or less a linear trend as shown in the figure. The calculated maximum and minimum equivalent stress behavior with respect to temperature is shown in Figure 5b. As seen in the figure, the cladding reaches its proportional limit and exhibits plastic deformation during the cooling process. The calculated equivalent stress is $55.2 \mathrm{MPa}$ for the cladding material, while it is approximately $320 \mathrm{MPa}$ for the fuel foil. Between $560{ }^{\circ} \mathrm{C}$ and $300{ }^{\circ} \mathrm{C}$, the fuel and cladding exhibit similar trends. However, after the temperature drops below $300{ }^{\circ} \mathrm{C}$, the calculated stresses for the fuel and the cladding begin to diverge. This divergence would generate stress gradients along the interface. This implies that unless a high degree of bonding is achieved above $300{ }^{\circ} \mathrm{C}$, the stress gradients at the interface would hinder further strengthening.

Figure 6 presents the equivalent stress distribution for the fuel foil (Figure 6a) and the cladding (Figure 6b). In Fig 6a, especially close to fuel foil ends, higher stresses can be seen. The maximum equivalent stress was computed to be approximately $320 \mathrm{MPa}$ for this region. Along the fuel edges, the equivalent stresses were computed to be lower in magnitude compared to those on the bonding faces, varying with location from approximately $160 \mathrm{MPa}$ to $320 \mathrm{MPa}$. Similarly, Figure 6b shows an equivalent stress field on the cladding. The calculated maximum equivalent stress is approximately $55 \mathrm{MPa}$. Cladding material over the fuel region exhibits complete yielding (showed by red). In general, the cladding shows compliant behavior. It can be implied that residual stresses on the plate are not dominated by cladding due to its compliant mechanical properties.

Calculated stress fields were treated as initial conditions for subsequent simulations. Hence, all stress components $\left(\sigma_{\mathrm{xx}}, \sigma_{\mathrm{yy}}\right.$, $\left.\sigma_{\mathrm{zz}}, \tau_{\mathrm{xy}}, \tau_{\mathrm{xz}}, \tau_{\mathrm{yz}}\right)$ for both the cladding and the fuel foil were implemented into the Finite element formulations of thermal annealing and in-service simulations. 

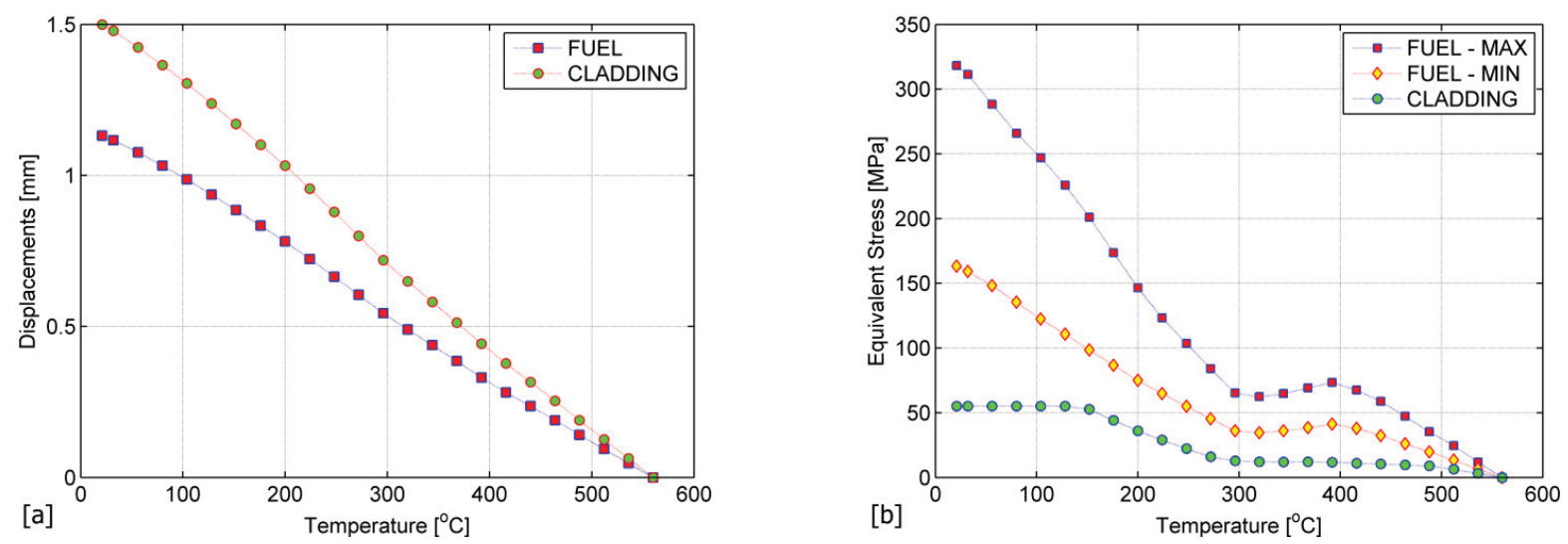

Figure 5 Transient results (a) Total displacements (b) Equivalent stresses
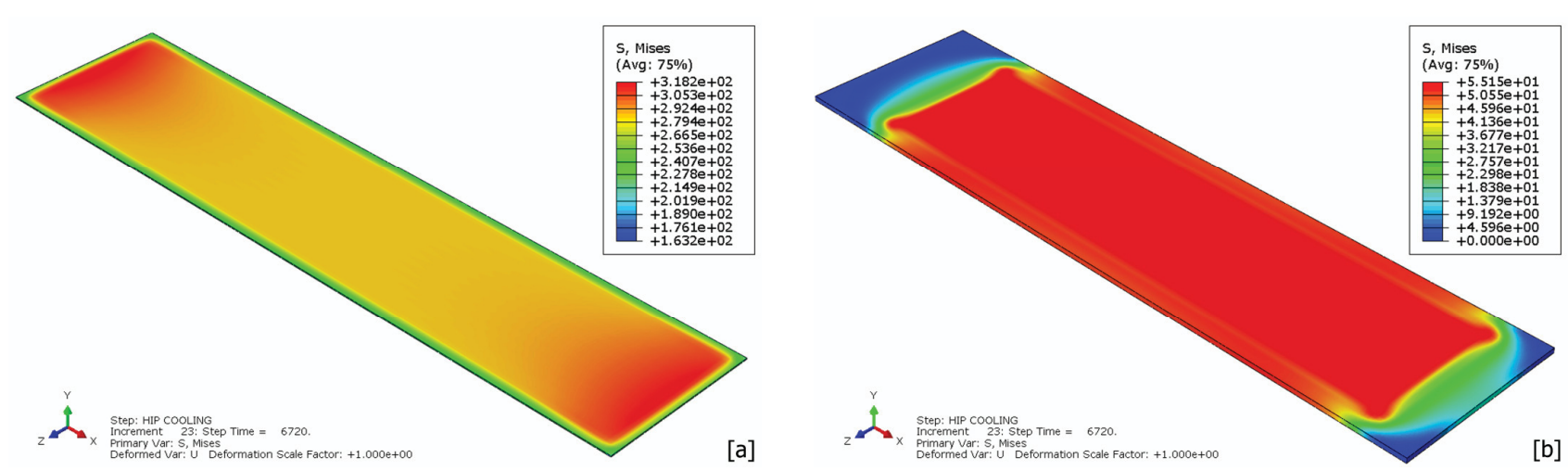

Figure 6 Contour plots for equivalent stress [MPa] fields on (a) Fuel foil (b) Cladding

Additional simulations were performed to investigate the effects of cooling rate on residual stresses. Four additional cooling durations were selected and simulated: 1.5 hour, 3 hours, 6 hours and 12 hours. Results of these simulations have indicated that thermal creep does not reduce the residual stresses significantly for cooling times less than 12 hours. Data from the simulations that include thermal creep of the cladding suggests that accounting for creep stress relaxation still results in stresses in excess of yield after cooling.

\subsection{BLISTER SIMULATION}

First, results of the HIP simulation were implemented in to the formulation of the model to include the residual stresses caused by the fabrication process. Three distinct stages were considered for annealing simulation. The heating stage increases the temperature from $21^{\circ} \mathrm{C}$ to $500{ }^{\circ} \mathrm{C}$ in 100 minutes (heating rate of $4.8{ }^{\circ} \mathrm{C} / \mathrm{min}$ ), the holding stage keeps the temperature steady at $500{ }^{\circ} \mathrm{C}$ for 60 minutes; and finally, the cooling stage reduces the temperature to $21^{\circ} \mathrm{C}$ in 100 minutes (cooling rate of $4.8^{\circ} \mathrm{C} / \mathrm{min}$ ). In order to increase the accuracy of the results, thermal creep was considered for all three stages.

\subsubsection{Transient Results}

Figure 7 shows calculated displacements and equivalent stress history during the thermal cycling process. From figure 7a, it can be seen that fuel exhibits approximately $1.05 \mathrm{~mm}$ total displacement $(0.526 \mathrm{~mm}$ with respect to volumetric center) while cladding gives approximately $1.37 \mathrm{~mm}(0.689 \mathrm{~mm}$ with respect to volumetric center) when the temperature reaches to its peak. In Figure $7 \mathrm{~b}$, the calculated equivalent stress response with respect to temperature and time is shown. In figure $7 \mathrm{~b}$, it can be seen that the fuel foil compromises an equivalent stress of $320 \mathrm{MPa}$ and the cladding has an equivalent stress of 55 $\mathrm{MPa}$ as an initial state (discussed in HIP section). Both cladding and fuel materials exhibit stress relaxations during the thermal loading. It seems, from $21^{\circ} \mathrm{C}$ to approximately $300{ }^{\circ} \mathrm{C}$, relaxation of foil is more rapid compared to relaxation of cladding. This trend starts to be linear at around $300{ }^{\circ} \mathrm{C}$. When the annealing temperature reaches to $500{ }^{\circ} \mathrm{C}$, the fuel foil manifests an equivalent stress of $39.4 \mathrm{MPa}$ and the cladding exhibits an equivalent stress of $8.64 \mathrm{MPa}$. During the hold period, the effects of thermal creep become more evident. The maximum equivalent stress of the fuel drops to $32.9 \mathrm{MPa}$, while equivalent stress of cladding is reduced to $6.69 \mathrm{MPa}$. 


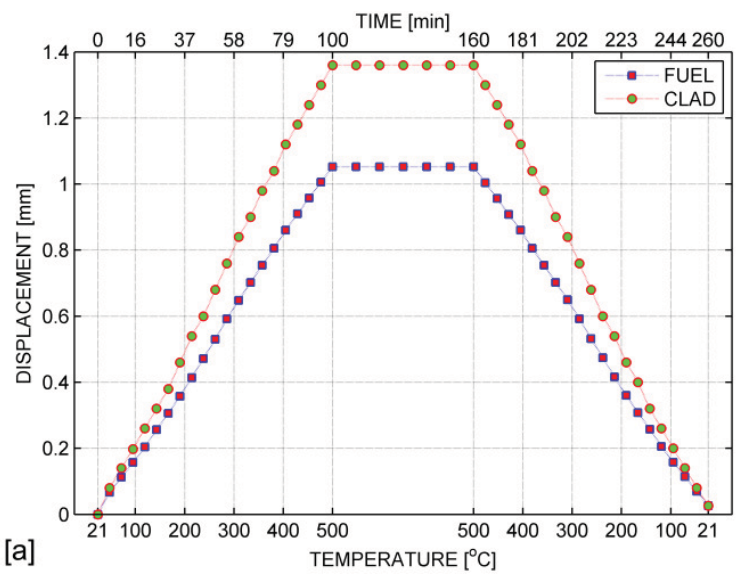

Figure 7 History outputs during thermal annealing (a) Total displacements (b) Equivalent stresses

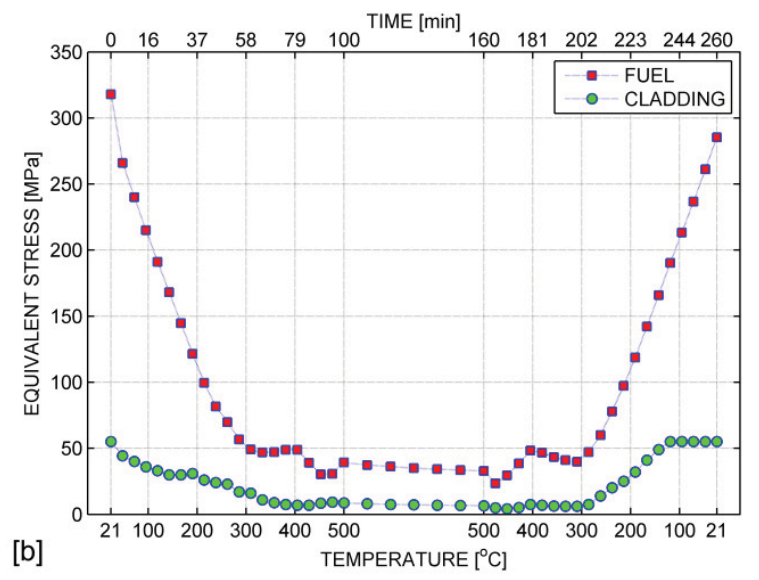

During the cooling period, fuel and cladding materials show similar trend with the heating period. By the end of the cooling period, the fuel foil gives an equivalent stress of $285 \mathrm{MPa}$. This implies that the thermal cycling process causes approximately $10 \%$ reduction on the fabrication induced residuals. Furthermore, from the figure, the cladding material reaches to its proportional limit and exhibits further plastic deformation (in addition to plastic strains caused by the fabrication). From the figure, it can be seen that stress trend of the cladding follows the yield curve of AL6061-TO.

\subsubsection{End of heating period}

Figure 8 presents the equivalent stress distribution for the fuel foil and the cladding materials (Figure $8 \mathrm{a}$ and $8 \mathrm{~b}$ respectively) at the end of heating period. In Figure 8a, especially close to foil corners and edges, a higher stress concentration was observed. The maximum equivalent stress was computed to be approximately $40 \mathrm{MPa}$ for these hot spots. Two linear regions slightly inside the long edges were identified as possible Blister regions. The bonding faces along the thickness (thin sides), the equivalent stresses were computed to be lower in magnitudes (approximately $8 \mathrm{MPa}$ ) compared to those on the bonding faces (top and bottom). Similarly, figure $8 \mathrm{~b}$ shows the equivalent stress mapping of the cladding. The calculated maximum equivalent stress is approximately $9 \mathrm{MPa}$. Cladding material over the fuel region exhibits higher stress magnitudes (showed by warmer colors). Similarly, two linear regions (showed in darker red) were identified as possible blister regions.

\subsubsection{End of holding period}

Hold period considers the plates for 60 minutes at $500{ }^{\circ} \mathrm{C}$. Even though the temperature of the plates is constant during the hold period, results were reviewed to investigate the effects of thermal creep. It was found that there are slight reductions in stress magnitudes at the end of the holding period. On the other hand, magnitudes of the displacements did not change during the hold period. Total displacement for the fuel was computed to be $1.05 \mathrm{~mm}$ and $1.37 \mathrm{~mm}$ for the cladding with respect to reference configuration.

Figure 9 presents the equivalent stress distribution for the fuel foil (figure 9a) and the cladding (figure 9b). It seems that thermal creep causes slight stress relaxation on the foil as shown in figure 9a. The maximum equivalent stress was computed to be $39.3 \mathrm{MPa}$ before the hold period, and, it is now reduced to $32.9 \mathrm{MPa}$ by the end of the holding period. In addition, stress concentrations on several locations were clearly visible on the fuel foil at the end of the heating period (as shown in Figure 8a). It seems stresses on the regions (inside of the long transverse edge) are relaxed. Though there is a reduction in magnitude, four spots which are close to the foil corners still have stress concentrations. Even though stress relaxation is not significant, similar trend can be seen for the cladding. The maximum equivalent stress is reduced to 6.69 $\mathrm{MPa}$ from 8.64 MPa.

\subsubsection{End of cooling period}

Cooling period reduces the temperature of the plates from 500 ${ }^{\circ} \mathrm{C}$ to the room temperature in approximately 100 minutes. It was computed that there is a slight elongation (approximately $0.013 \mathrm{~mm}$ with respect to reference) at the end of the annealing process. The major impact of the thermal cycling process is on the magnitudes of the final stresses. The thermal creep causes a noticeable stress relaxation especially on the fuel foil. Figure 10 shows the equivalent stress distribution for the fuel foil (Figure 10a) and the cladding material (Figure 10b). It seems thermal cycling causes approximately $10 \%$ stress reduction. Maximum equivalent stress for the fuel foil is reduced to $285 \mathrm{MPa}$ at the end of the thermal cycling process. As mentioned in HIP simulation, the maximum equivalent stress was $318 \mathrm{MPa}$ before the thermal annealing process. Similar reduction is valid for the minimum equivalent stress. Minimum equivalent stress is now reduced to $155 \mathrm{MPa}$ (from $163 \mathrm{MPa}$ ). Bonding regions along the thin faces (along thickness direction) of the foil has lower stresses in magnitude. 

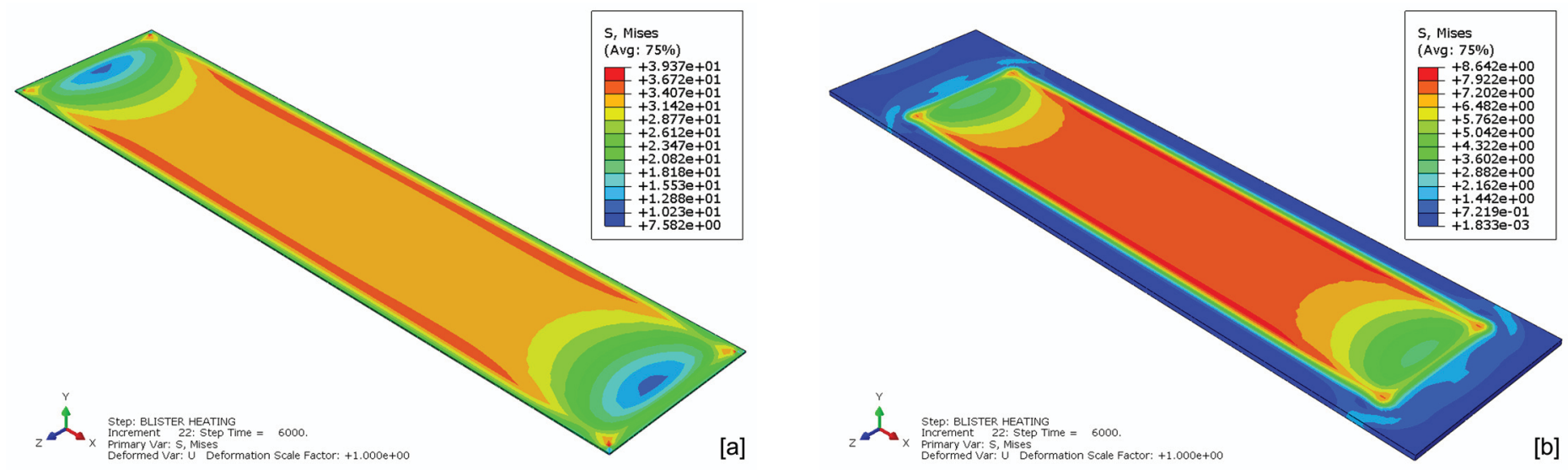

Figure 8 Equivalent stress [MPa] fields at the End of Heating Period (a) Fuel foil (b) Cladding
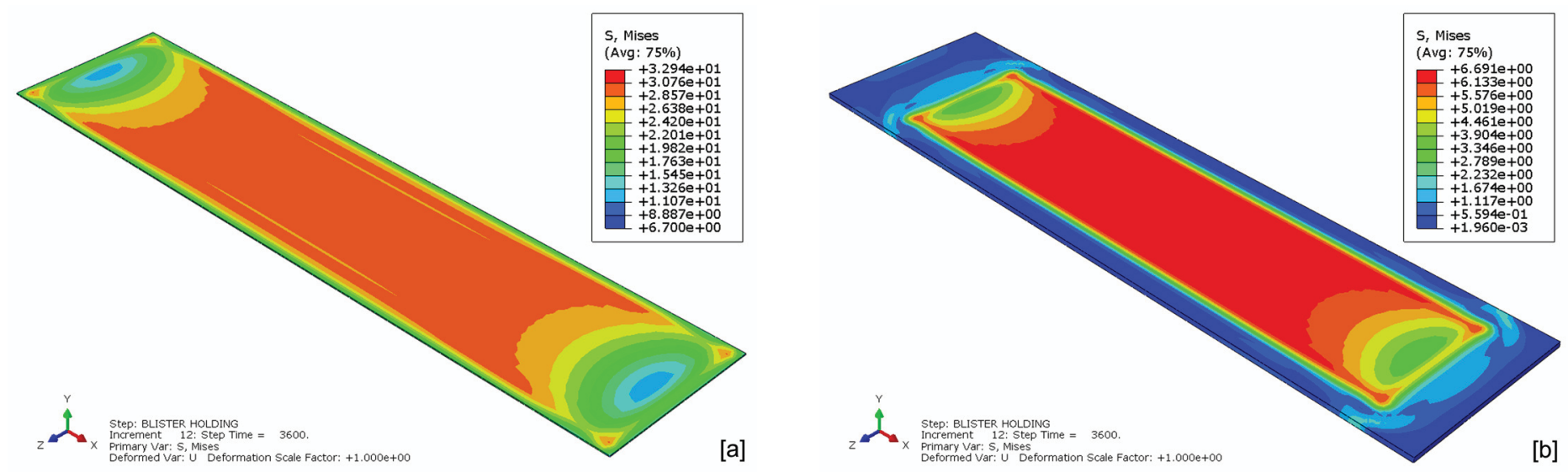

Figure 9 Equivalent stress [MPa] fields at the End of Holding Period (a) Fuel foil (b) Cladding
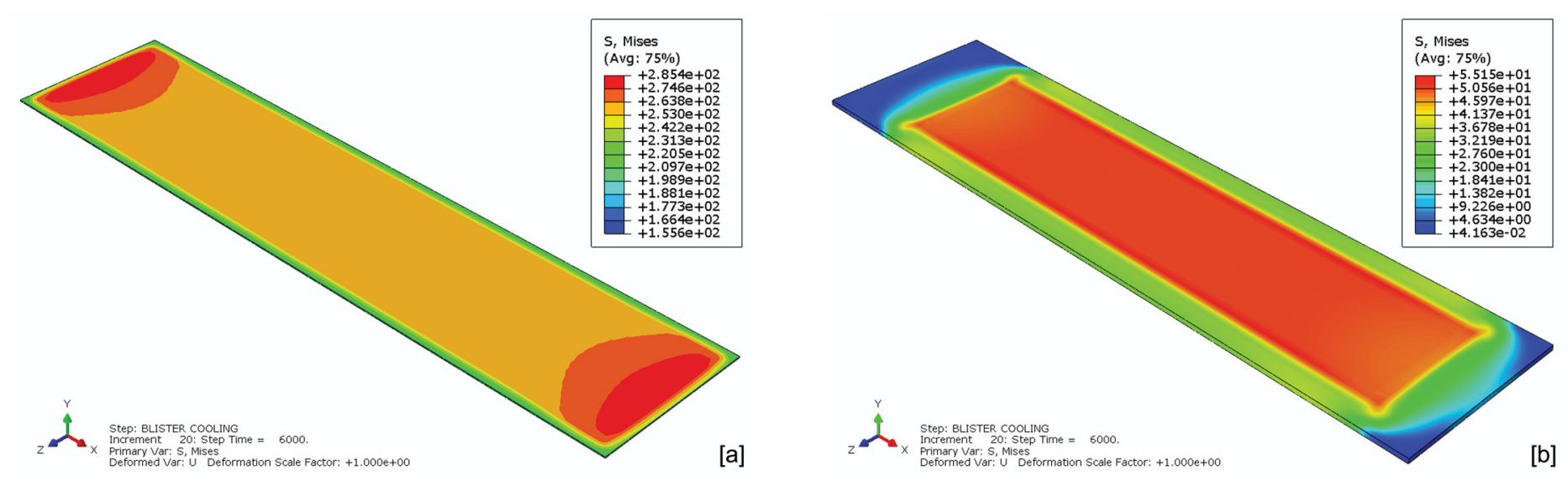

Figure 10 Equivalent stress [MPa] fields at the End of Cooling Period (a) Fuel foil (b) Cladding 


\subsection{IRRADIATION SIMULATION}

Irradiation model simulates the plates for 98 days under actual operating conditions. Finite element mesh and model presented in figure 4 was modified to account the irradiation effects. Furthermore, fluid thermal and structural interaction was considered. Results from the HIP simulation were included as initial condition. The power profile with respect to plate width (shown in Figure 3a) and volumetric heat generation rate with respect to time (shown in Figure $3 b$ ) were implemented via parametric expressions and they were assigned to the fuel region. Irradiation induced creep (for U10Mo), volumetric swelling rate (for $\mathrm{U} 10 \mathrm{Mo}$ ), volumetric heat generation and its swelling update (for U10Mo), thermal creep (for Al6061-TO) relations were implemented into the finite element formulation accordingly. Non-linear volumetric swelling strain rate was assigned to the fuel region via user defined FORTRAN subroutine. First temperature field of the fuel foil and cladding were computed. Calculated results were used as nodal forces to calculate the thermal stresses. Results were stored for every 24 hours of irradiation.

Figure 11 shows calculated temperature field for the fuel foil. It seems maximum temperature is $128{ }^{\circ} \mathrm{C}(401.6 \mathrm{~K})$ for the foil. Similarly, figure $11 \mathrm{~b}$ presents the temperature gradient at the

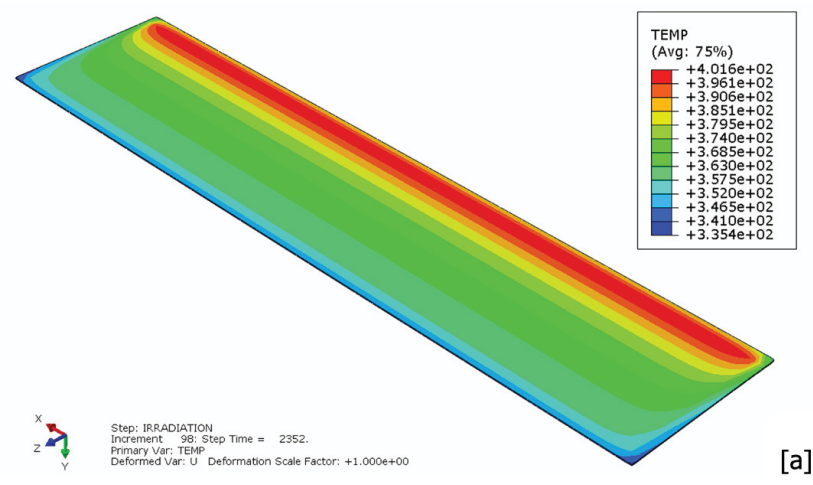

cross section (section cut of YZ plane) of the foil. Temperature profile caused by non-linear fission density can be seen.

Figure 12 gives equivalent stress history during the irradiation period and final displacement profile (end of irradiation period) along the thickness direction of the foil. Figure 12a implies that residual stresses (computed $318 \mathrm{MPa}$ in HIP simulation) caused by fabrication process evolves very rapidly and are reduced to approximately $240 \mathrm{MPa}$ in several days of irradiation. While fission swelling should increase the stresses on the fuel foil, it seems irradiation induces creep becomes more dominant and causes further stress relaxation. This trend can be seen in Figure 12a. Figure 12b present the final displacement profile for the fuel foil.

Figure 13 shows contour plots for the swelling strain (Figure 13a) and the calculated displacement field of the fuel foil at the end of the irradiation period (for 98 days of irradiation). A nonlinear fission profile (shown in Figure 3a) causes an exponential swelling and displacement behavior on the plates. In Figure 13a, it can be seen that far edge of the foil experiences approximately $20 \%$ swelling, while the opposite edge experiences much higher swelling strain (approximately 47\%). Final displacement field along the thickness direction account this swelling strain is shown in Figure $13 \mathrm{~b}$.

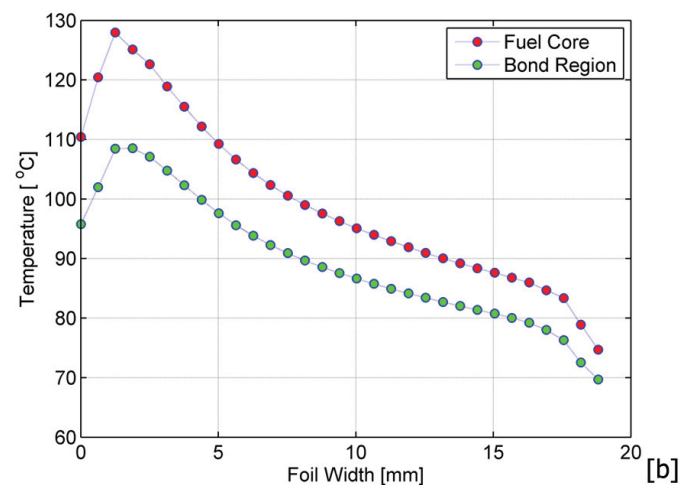

Figure 11 Temperature field for the fuel foil (a) 3D Surface mapping [in K] (b) Section cut (on YZ plane)
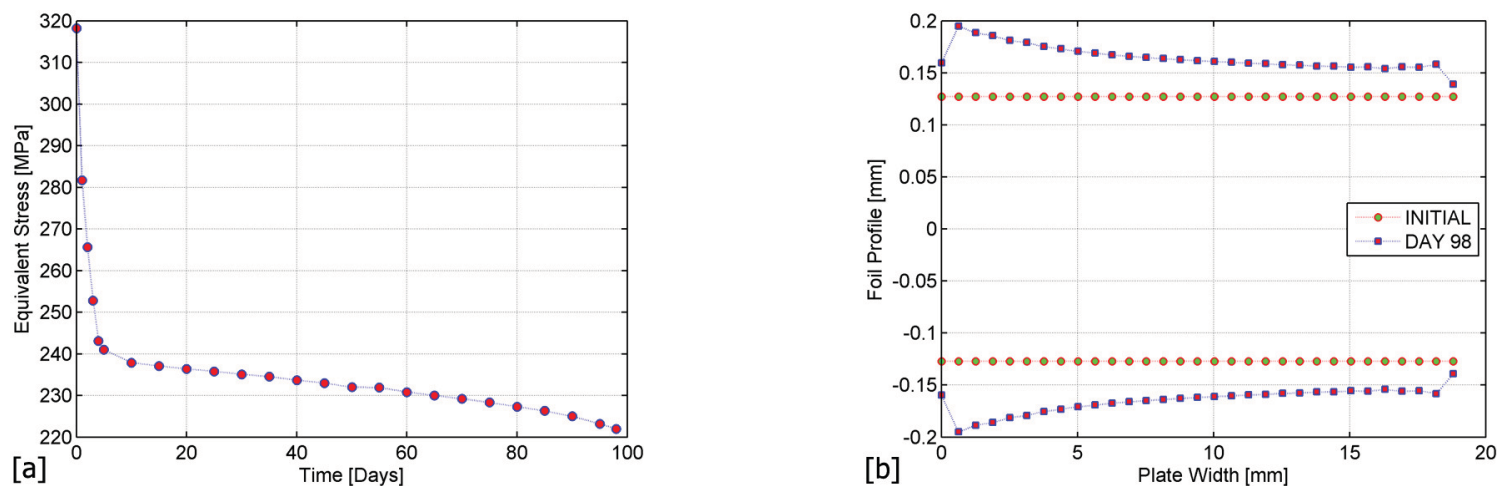

Figure 12 Fuel Foil (a) Equivalent stress history (b) Displacement [mm] at the thickness direction (Day 98) 

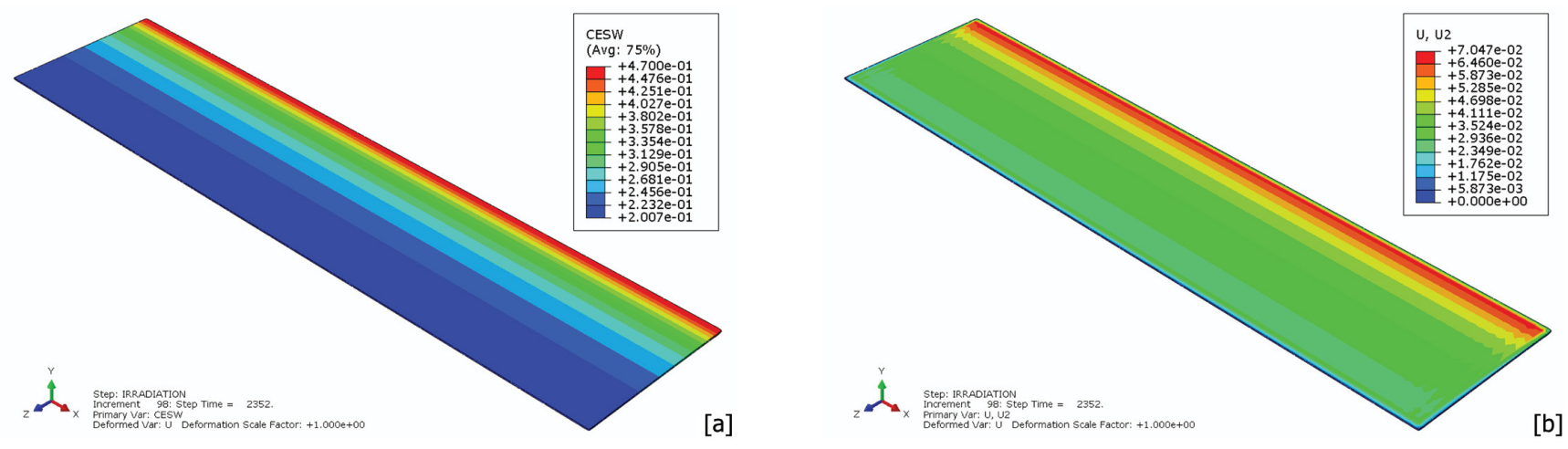

Figure 13 Contours for an irradiated (98 days) plate (a) Swelling strain (b) Displacement [mm] on thickness direction

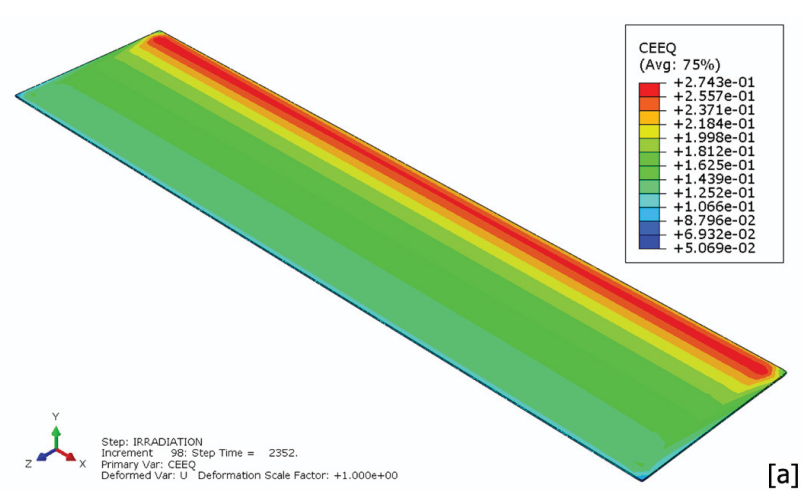

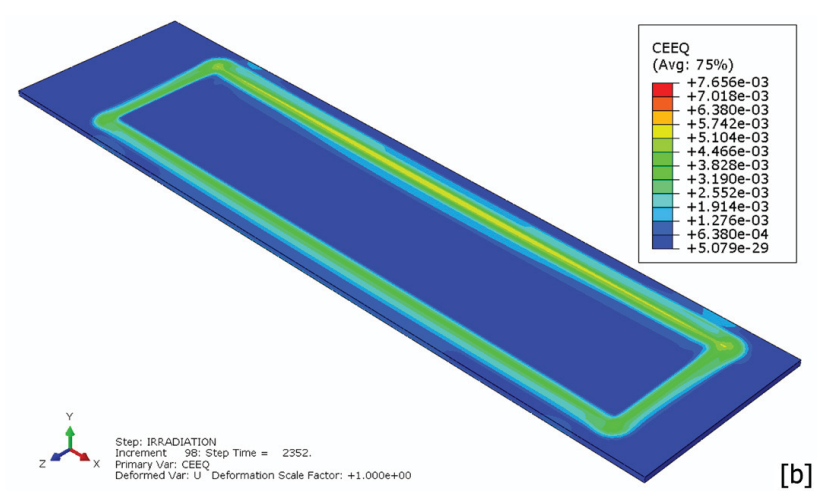

[b]

Figure 14 Equivalent creep strains, 98 days of irradiation (a) Irradiation creep of fuel (b) Thermal creep of cladding

Figure 14 shows the equivalent creep strain fields for the foil and the cladding. Figure 14a gives irradiation induced creep of the foil. Maximum irradiation induced creep strain is approximately $27 \%$ for the foil. Figure $17 \mathrm{~b}$ presents thermal creep strain of cladding materials. Maximum equivalent thermal creep strain is located at the bonding faces and it is approximately $0.75 \%$.

To show the evolution of the stress fields during the irradiation process, equivalent stress contours were gathered and presented in Figure 15 through Figure 22.

Figure 15 presents equivalent stress fields for the fuel and cladding materials when the reactor starts (1 hour of irradiation). Maximum stress of the foil is now reduced to 281 $\mathrm{MPa}$ due to temperature field on the plates. Furthermore, a slight stress relaxation (refer to calculated residual stresses presented in HIP simulation) on the cladding can be seen. Figure 16 presents equivalent stress fields for the fuel (figure $16 \mathrm{a}$ ) and cladding (figure 16b) at the end of 1 day of irradiation. Maximum equivalent stress for the fuel foil is reduced to 259 $\mathrm{MPa}$. In figure 16b, it seems thermal creep causes approximately $10 \%$ stress relaxation on the cladding material.

Figure 17 shows equivalent stress fields at the end of 5 days of irradiation. On long transverse edge of the fuel, due to higher neutron flux and temperature, a stress concentration becomes more noticeable. Maximum equivalent stress for this region is $241 \mathrm{MPa}$. It seems that in day 5, volumetric swelling starts to manifest itself. This causes a slight increase in stress magnitude for the cladding material. Equivalent stress fields for the 10 days of irradiation are shown in Figure 18. A slight stress relaxation (237 MPa maximum) on the foil can be seen. Figure 19 gives equivalent stress fields on the plates for 30 days of irradiation. Maximum stress was computed to be $235 \mathrm{MPa}$ for the fuel. It seems swelling of the fuel causes further yielding on the cladding. Figure 20 shows the contour mapping for 60 days of irradiation. Even though volumetric swelling strain reaches to significant values, irradiation creep continues to cause stress relaxation on the foil. For day 60, maximum equivalent stress was computed to be $230 \mathrm{MPa}$ for the foil. Yielded regions are noticeable on the cladding as shown in figure 20b. Equivalent stress fields for the plates under 90 days of irradiation are shown in Figure 21. Maximum equivalent stress for the foil is reduced to $225 \mathrm{MPa}$. Finally, figure 22 shows the equivalent stress fields for the fuel (figure 22a) and cladding (figure 22b) at end of the irradiation period (98 days). A complete evolution of the stress field on cladding is visible. It seems there is a stress increase over the bonding area caused by the volumetric increase of the fuel foil. A further relaxation of the foil was noticed. It seems maximum equivalent stress for the foil is reduced to $220 \mathrm{MPa}$ (as opposed to $225 \mathrm{MPa}$ in Day 90). 

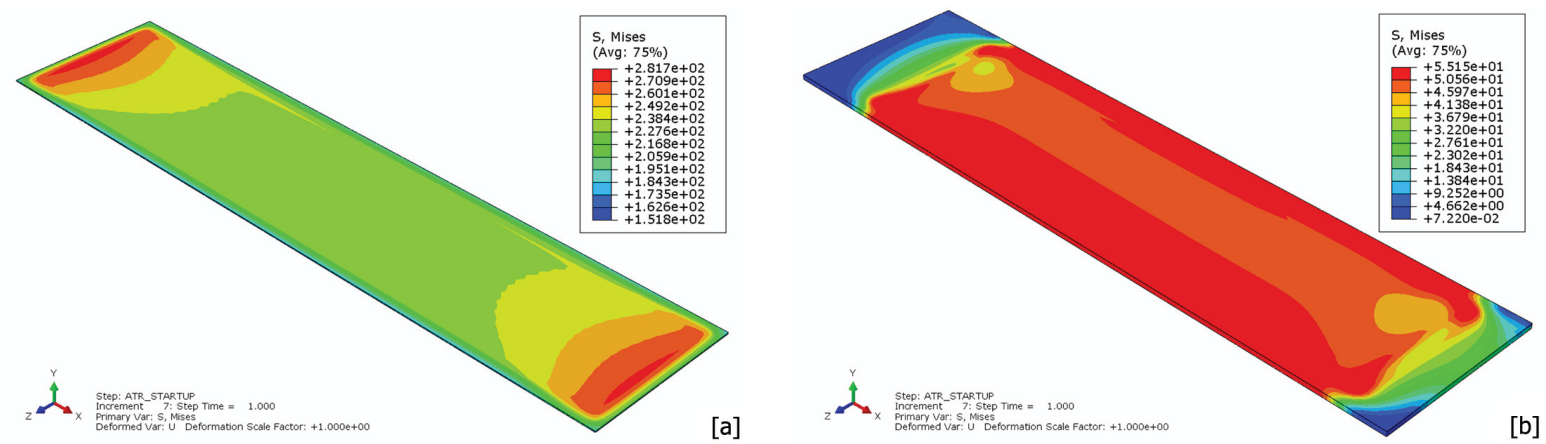

Figure 15 Equivalent Stress [MPa] Fields, 1 Hour Irradiation (Heat-up) (a) Fuel Foil (b) Cladding
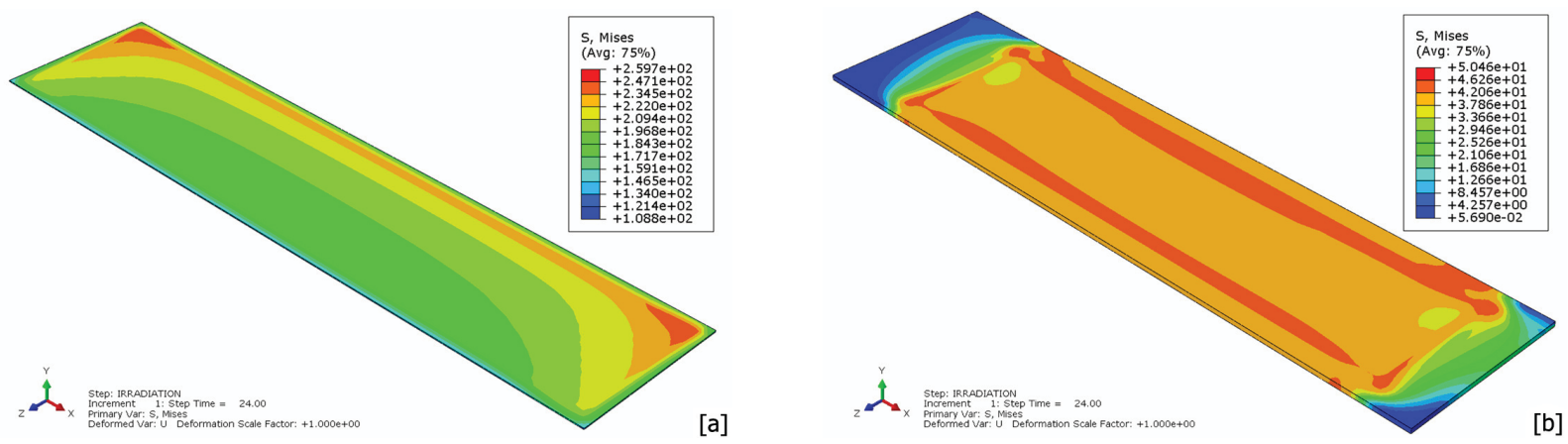

Figure 16 Equivalent Stress [MPa] Fields, 24 Hours (1 Day) of Irradiation (a) Fuel Foil (b) Cladding
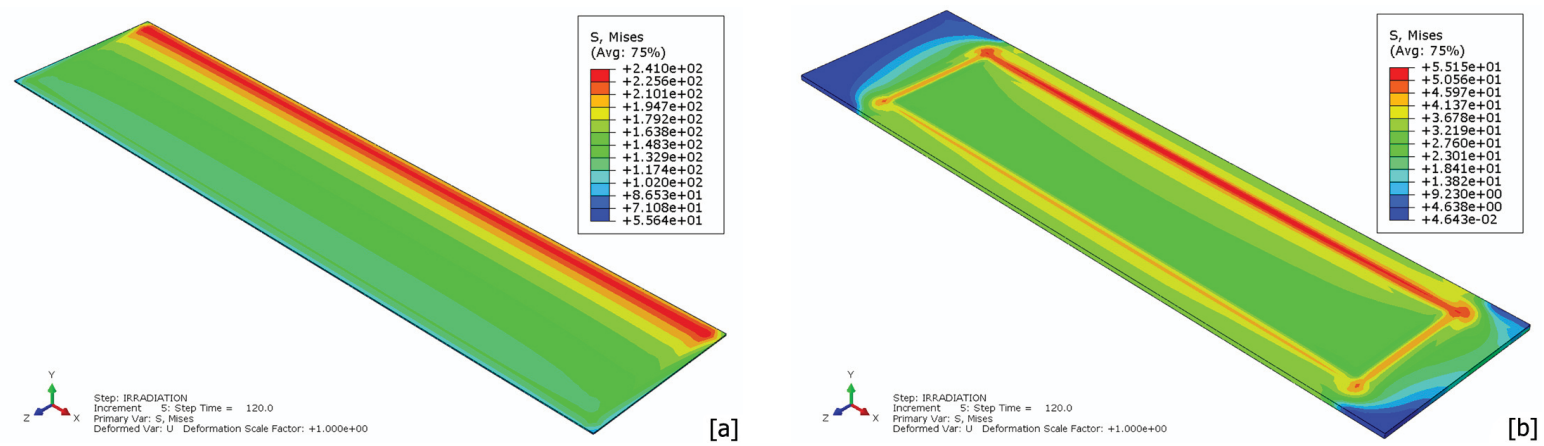

Figure 17 Equivalent Stress [MPa] Fields, 120 Hours (5 Day) of Irradiation (a) Fuel Foil (b) Cladding
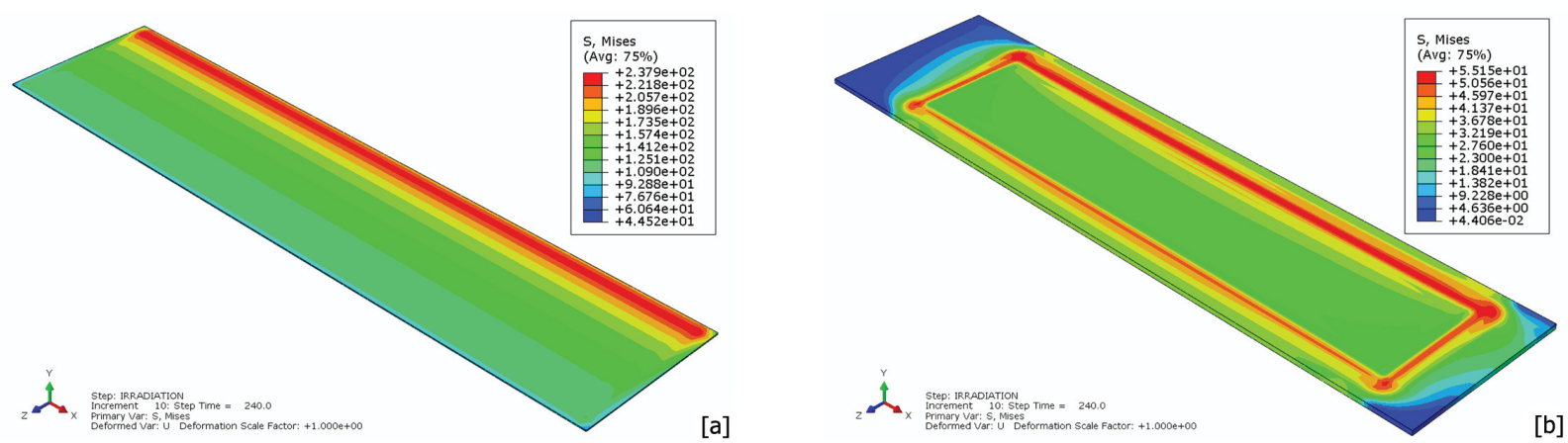

Figure 18 Equivalent Stress [MPa] Fields, 240 Hours (10 Days) of Irradiation (a) Fuel Foil (b) Cladding 

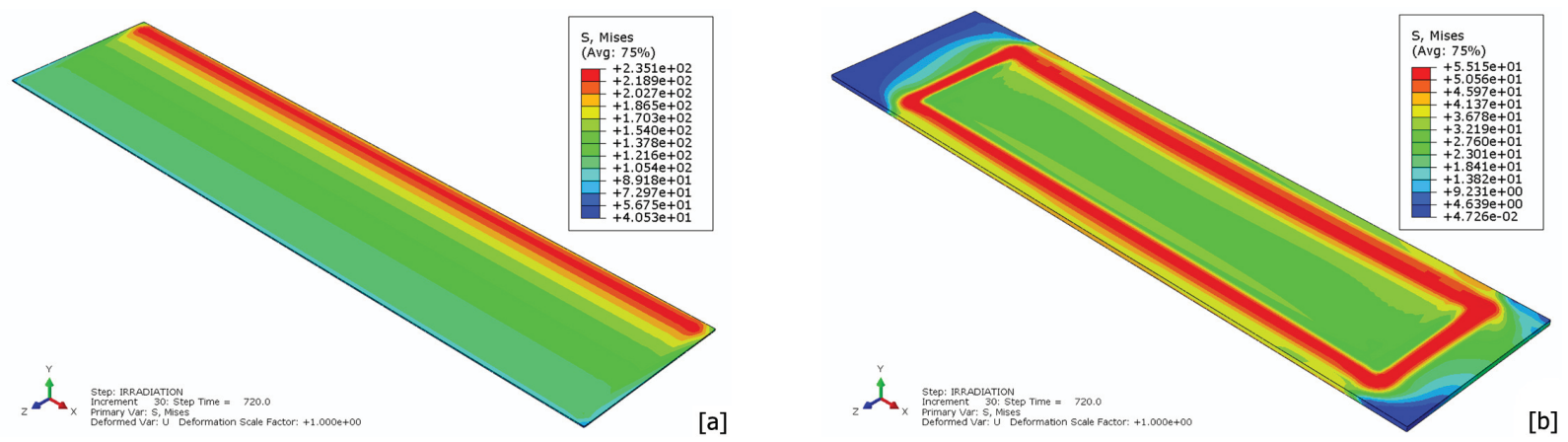

Figure 19 Equivalent Stress [MPa] Fields, 720 Hours (30 Days) of Irradiation (a) Fuel Foil (b) Cladding
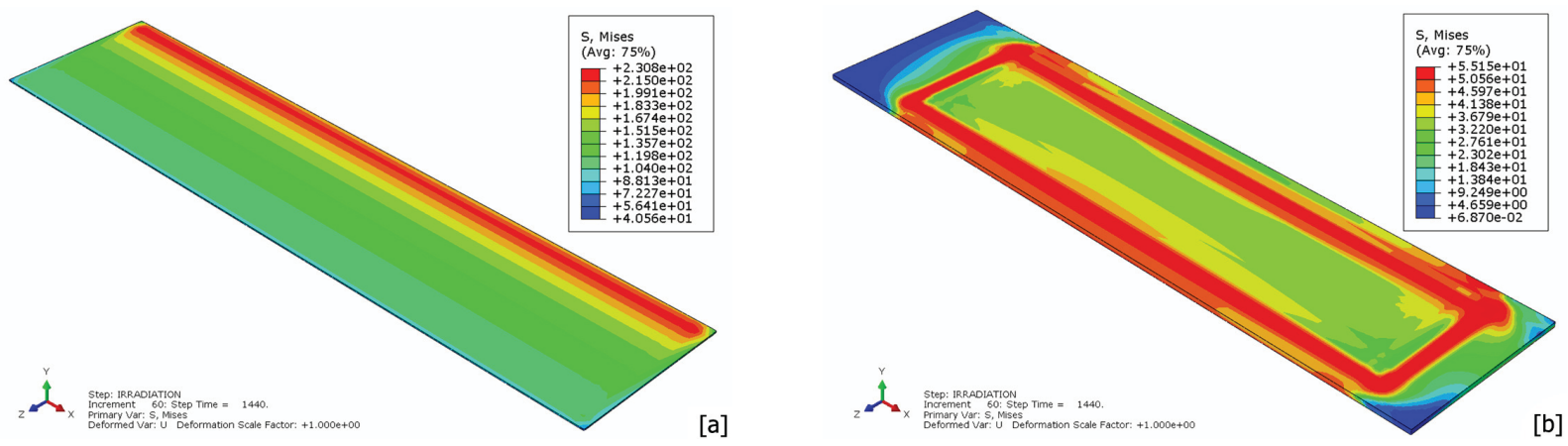

Figure 20 Equivalent Stress [MPa] Fields, 1440 Hours (60 Days) of Irradiation (a) Fuel Foil (b) Cladding
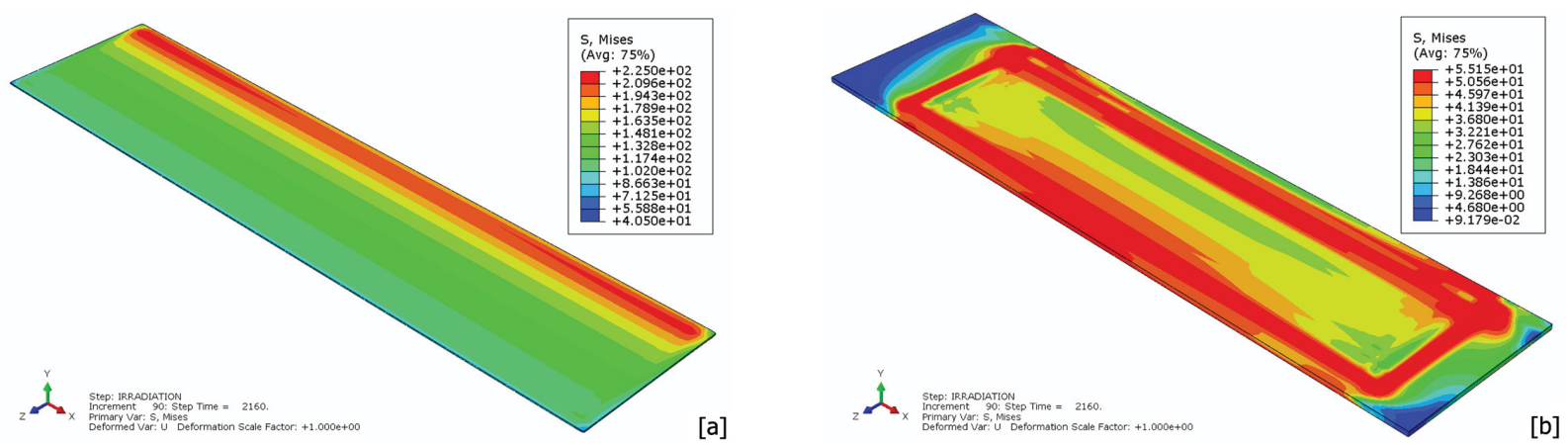

Figure 21 Equivalent Stress [MPa] Fields, 2160 Hours (90 Days) of Irradiation (a) Fuel Foil (b) Cladding
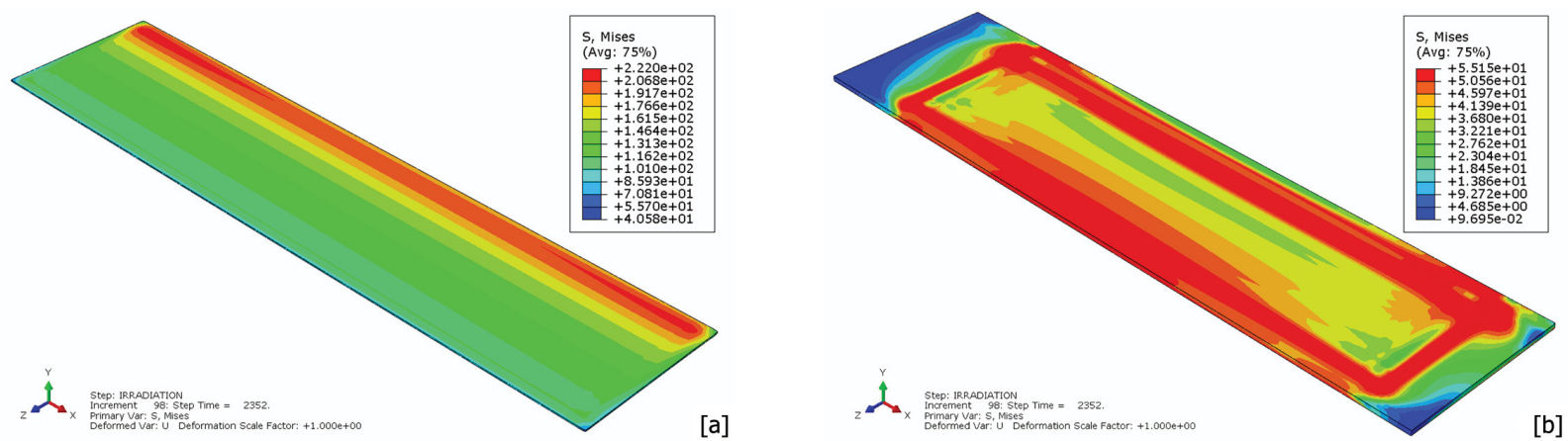

Figure 22 Equivalent Stress [MPa] Fields, 2352 Hours (98 Days) of Irradiation (a) Fuel Foil (b) Cladding 


\section{CONCLUSIONS}

Mechanical behavior of the monolithic fuel plates was investigated. Three distinct processes of the plates were considered (Fabrication, In-service and Thermal Cycling of the plates). By HIP model, the thermo-mechanical behavior of the monolithic fuel plates during the fabrication process was simulated. The analysis demonstrated that the residual stresses are significant. Differences in the coefficient of thermal expansion between the cladding and the foil and high stiffness of the U-10Mo foil are the primary causes of these residual stresses. The simulation indicates that the aluminum cladding material is subjected to tensile stresses that exceed its proportional limits during cooling. The U-Mo fuel foil is subjected to compressive stresses and remains below yield. The simulations also indicate the anticipated magnitude of the stress gradients at the fuel/cladding interface. Four distinct cooling rates were investigated and were found to have little effect on the residual stresses. By Blister model, plate behavior during thermal annealing was studied. It was found that residual stresses would dominate the mechanical behavior of a monolithic plate. Existence of the stress gradients at the interface region is noted. Especially closer to fuel foil ends, high stress concentration on the foil was observed. During the blister annealing, there is a change in stress directions occurs at approximately $400{ }^{\circ} \mathrm{C}$. This temperature was identified as a transition temperature that a plate would become more susceptible. Possible regions susceptible for the development of Blisters were noted. In addition, a stress relaxation caused by thermal creep was noted. Finally, thermo-mechanical behavior of the monolithic fuel mini-plates under in-reactor conditions was simulated. For this, a new thermal creep relation was developed to cover the long term behavior. Irradiation induced creep formulation was evaluated and implemented by using a time hardening power law. Non-linear swelling formulation was developed. Swelling was introduced to the fuel foil via user defined subroutine. Heat generation was re-formulated to account the volumetric swelling. Temperature field was identified via Thermal-Structural interaction. Heat transfer coefficient between the cladding and coolant was computed via Dittus-Boelter correlation. Once it is identified, temperature field was used as thermal load for the foil and the cladding. The analysis demonstrated that the relaxation due to irradiation induced creep is balanced by the stresses caused by the volumetric foil swelling. It was found that irradiation induced creep causes continuous stress relaxation on the plates.

\section{NOMENCLATURE}

$A \quad$ Power law multiplier

$C_{p} \quad$ Specific Heat

$D_{i j k l} \quad$ Elasticity matrix

$D_{H} \quad$ Hydraulic diameter

$E \quad$ Modulus of Elasticity

$F \quad$ Volume force field

$G \quad$ Shear Modulus $h \quad$ Heat Transfer Coefficient

$k \quad$ Thermal conductivity

$m \quad$ Time exponent

$n \quad$ Stress exponent

$\mathrm{Nu} \quad$ Nusselt Number

$Q \quad$ Heat source

$P \quad$ Pressure

$\mathrm{Pr} \quad$ Prandtl Number

Re Reynolds Number

$t \quad$ Time

$T \quad$ Temperature

$u_{i j} \quad$ Displacement

$\alpha_{k l} \quad$ Tensor for coefficient of thermal expansion

$\varepsilon_{i j} \quad$ Strain Tensor

$\overline{\mathcal{E}} \quad$ Equivalent plastic strain

$\dot{\bar{\varepsilon}}^{c r} \quad$ Equivalent creep strain rate

$\rho \quad$ Density

$\eta \quad$ Dynamic viscosity

$\sigma_{i j}, \quad$ Stress tensor

$\sigma_{i j} \quad$ Deviatoric Kirchhoff stress

$\sigma_{s} \quad$ Yield stress

U Poisson's ratio

() $)^{\text {th }}$ Thermal

()$^{c r} \quad$ Creep

()$^{\text {in }} \quad$ Initial

()$^{i r} \quad$ Irradiation

()$^{p l} \quad$ Plastic

\section{US DEPARTMENT OF ENERGY DISCLAIMER}

This manuscript has been authored under Contract No. DEAC07-05ID14517 with the US Department of Energy. The US Government retains and the publisher, by accepting the article for publication, acknowledges that the US Government retains a nonexclusive, paid-up, irrevocable, world-wide license to publish or reproduce the published form of this manuscript, or allow others to do so, for US Government purposes. This information was prepared as an account of work sponsored by an agency of the U.S. Government. Neither the U.S. Government nor any agency thereof, nor any of their employees, makes any warranty, express or implied, or assumes any legal liability or responsibility for the accuracy, completeness, or usefulness of any information, apparatus, product, or process disclosed, or represents that its use would not infringe privately owned rights. References herein to any specific commercial product, process, or service by trade name, trademark, manufacturer, or otherwise, does not necessarily constitute or imply its endorsement, recommendation, or favoring by the U.S. Government or any agency thereof. The views and opinions of authors expressed herein do not necessarily state or reflect those of the U.S. Government or any agency thereof. 


\section{REFERENCES}

[1] Snelgrove J.L., Hofman G.L., Meyer M.K., Trybus C.L., Wienceck T.C., "Development of Very-High-Density Low Enriched Uranium Fuels", Journal of Nuclear Engineering and Design, (1997).Vol.178, pp. 119-126.

[2] Lee D.B., Kim K.H., Kim C.K., "Thermal Compatibility Studies of Unirradiated U-Mo Alloys Dispersed in Aluminum," Journal of Nuclear Materials, (1997), Vol.250, pp.79-82.

[3] Park J.M., Kim K.H., Kim C.K., Meyer M.K., Hofman G.L., Strain R.V., "The Irradiation Behavior of Atomized U-Mo Alloy Fuels at High Temperature", Journal of Metals and Materials International, (2001), Vol.7, No.2, pp. 151-15.

[4] Meyer M.K., Hofman G.L., Hayes S.L., Clark C.R., Wienceck T.C., Snelgrove J.L., Strain R.V., Kim K.H., "Low Temperature Irradiation Behavior of U-Mo Alloy Dispersion Fuel", Journal of Nuclear Materials, (2002), Vol.304, pp. 221236.

[5] M. H. Bocanegra-Bernal, "Hot Isostatic Pressing Technology and Its Application to Metals and Ceramics", Journal of Materials Science, (2004), Vol. 39, pp. 6399- 6420.

[6] H. Yamada, H. Kawamura, K. Tsuchiya, G. Kalinin, Y. Nagao, S. Sato, and K. Mohri, "The Neutron Irradiation Effect on Mechanical properties of HIP Joint Material," Journal of Nuclear Materials, (2004), Vol. 335, pp. 33-38.

[7] Jan-Fong Jue, Blair H. Park, Curtis R. Clark, Glenn A. Moore, Dennis D. Keiser, " Fabrication of Monolithic RERTR Fuels by Hot Isostatic Pressing", Journal of Nuclear Technology, (2010), Vol. 172, No. 2, pp. 204-210.

[8] Yeon Soo Kim, G.L. Hofman, J. Rest, Y.S. Choo. "Analysis of Fission Gas Bubbles and Microstructures of Irradiated U-Mo Fuel", RERTR 2009 - 31st International Meeting on Reduced Enrichment for Research and Test Reactors, (2009).

[9] G.l. Hofman, Yeon Soo Kim, A.B. Robinson. "Fission Induced Swelling and Creep of Uranium Molybdenum Alloy Fuel". RRFM 2009 - $13^{\text {th }}$ Research Reactor Fuel Management Conference, (2009), ISBN 978-92-95064-07-2, pp. 74-78.

[10] R. Hussein, K. Ha, P. Fazio, "Thermal Stresses in Sandwich Plates", Journal of Thermal Stresses, (1989), Volume 12, No. 3, pp. 333-349.

[11] Jurgen Malzbendera, "Mechanical and Thermal Stresses in Multilayered Materials", Journal of Applied Physics, (2004), Volume 95, No. 4, pp. 1780-1782.

[12] Antonio Pantano and Ronald C. Averill, "A 3D Zig-Zag Sublaminate Model for Analysis of Thermal Stresses in
Laminated Composite and Sandwich Plates", Journal of Sandwich Structures and Materials, (2000), Volume 2, pp. 288312 .

[13] Jaroslav Mackerle, "Finite Element Analyses of Sandwich Structures: A Bibliography", Journal of Engineering Computations, (2002), Volume 19, Issue: 2, pp. 206-245.

[14] Rest J., Kim Y. S., Hofman G. L., Meyer M. K., Hayes S. L., "U-Mo Fuels Handbook v.1.0", Argonne National Laboratory Internal Report. (2006).

[15] D.E. Burkes, C.A. Papesch, A.P. Maddison, T. Hartmann, F.J. Rice, "Thermo-physical properties of DU-10wt\%Mo alloys", J. of Nuclear Materials. (2010), Vol.403, pp. 160-166.

[16] D. E. Burkes, Ramprashad Prabhakaran, Thomas Hartmann, Jan-Fong Jue, Francine J. Rice, "Properties of DU$10 \mathrm{wt} \%$ Mo alloys subjected to various post-rolling heat treatments", Nuclear Engineering and Design, (2010), Vol. 240, Issue 6, pp. 1332-1339

[17] J. T. Mihalczo, "Reactivity Calibrations and Fission-Rate Distributions in an unmoderated, unreflected U-Mo Alloy Research Reactor", Oak Ridge National Laboratory, Internal Report, ORNL-TM-189, (1962)

[18] Waldron, M.B., Burnett, R.C., Pugh, S.F., "The Mechanical Properties of U-Mo Alloys", (1958), UK Atomic Energy Authority, Technical Report, AERE-M/B-2554.

[19] Polkinghorne S.T., Lacy J.M., "Thermophysical and Mechanical Properties of ATR Core Materials". EG\&G Idaho Inc., Internal Technical Report, (1991), PG-T-91-031.

[20] Zhang Z., Zhang H.W., "Material Behaviors and Mechanical Features in Friction Stir Welding Process", International Journal of Advanced Manufacturing Technology, (2007), Vol.35, pp.86-100.

[21] Kaufman, J. Gilbert, "Properties of Aluminum Alloys Fatigue Data and the Effects of Temperature, Product Form, and Processing", ASM International, (2008), pp.163-164

[22] Scott F. Miller, Albert J. Shih, "Thermo-Mechanical FEM of the Friction Drilling Process, Journal of Manufacturing Science and Engineering, ASME, (2007), Vol. 129, pp. 531-539

[23] Soundararajan, V., Zekovic, S., and Kovacevic, R., "Thermo-Mechanical Model with Adaptive Boundary Conditions for Friction Stir Welding of Al6061", International Journal of Machine Tools and Manufacture, (2005), Vol. 45, pp.1577-1587. 


\section{ANNEX A}

MATERIAL PROPERTY ${ }^{[14-23]}$ FOR FUEL FOIL (U10MO) AND CLADDING (AL6061-TO)

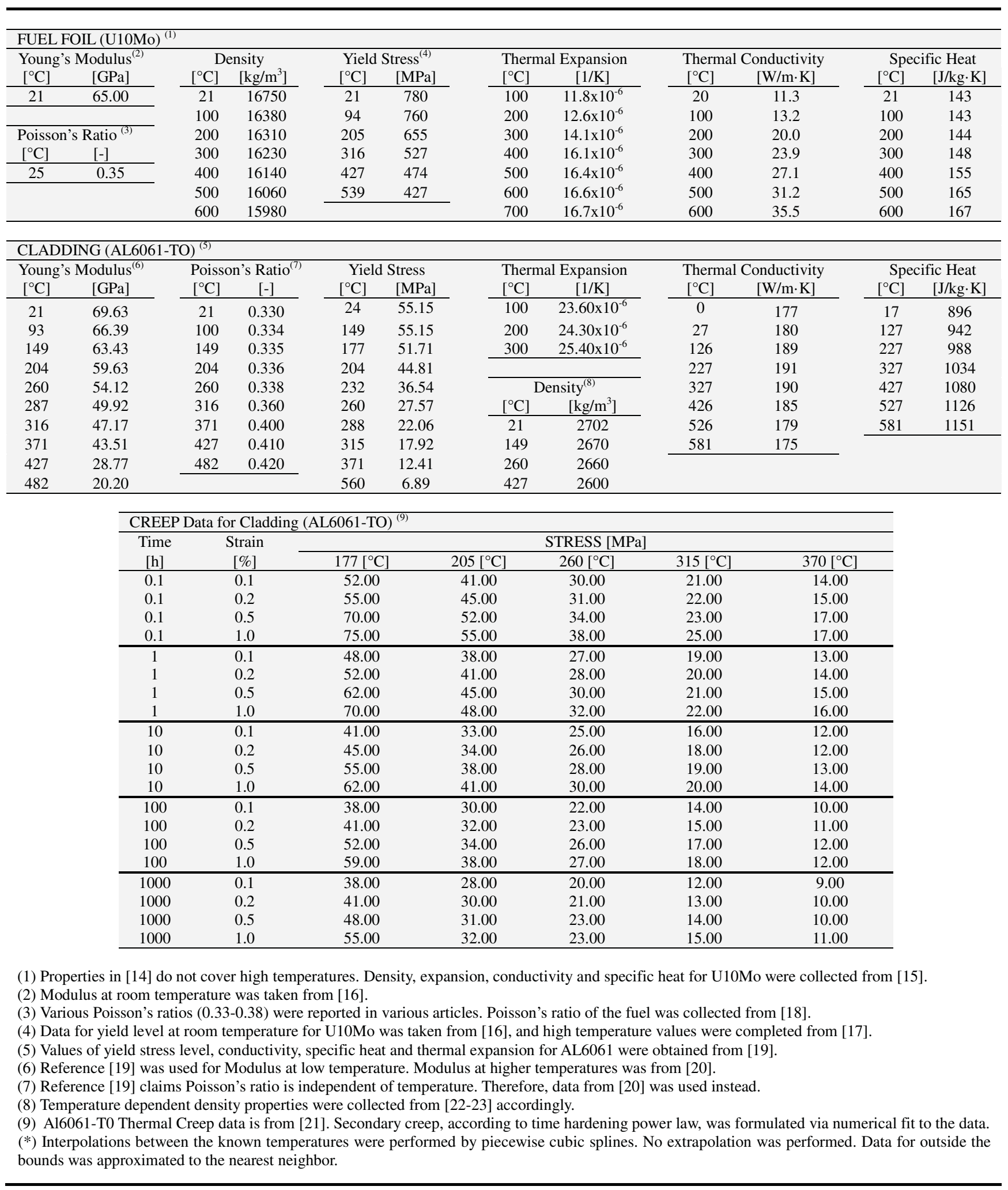

